\title{
ECORESIDENTE: EDUCAÇÃO AMBIENTAL PARA O FORTALECIMENTO DA SUSTENTABILIDADE ESCOLAR
}

\author{
Lucas da Silva ${ }^{1}$ \\ Jackson Araujo de Sousa ${ }^{2}$ \\ Antonio Breno Lopes da Silva ${ }^{3}$
}

Resumo: $O$ objetivo do presente trabalho é possibilitar o desenvolvimento de ações de Educação Ambiental, envolvendo a comunidade escolar, disseminando os princípios ecológicos e sustentáveis para se alcançar a racionalidade ambiental e a formação de sujeitos ecológicos no espaço escolar, tornando a escola mais sustentável. A pesquisa caracteriza-se como um estudo qualitativo, exploratório e descritivo, com enfoque na pesquisa-ação, seguindo algumas etapas, a saber: 1) Levantamento bibliográfico; 2) planejamento das ações; 3) realização das ações; e, 4) avaliação das ações desenvolvidas. Assim, os resultados evidenciam a importância e contribuição para a formação de sujeitos ecológicos, utilizando-se de estratégias e ações voltadas a Educação Ambiental em espaços escolares.

Palavras-chave: Ecoresidente; Educação Ambiental; Sustentabilidade.

Abstract: The objective of this work is to enable the development of environmental education actions, involving the school community, disseminating ecological and sustainable principles to achieve environmental rationality and the formation of ecological subjects in the school space, making the school more sustainable. The research is characterized as a qualitative, exploratory and descriptive study, with a focus on action research, following some steps, namely: 1) Bibliographic survey; 2) actions planning; 3 ) carrying out the actions; and, 4) evaluation of the actions developed. Thus, the results show the importance and contribution to the formation of ecological subjects, using strategies and actions aimed at environmental education in school spaces.

Keywords: Ecoresident; Environmental Education; Sustainability.

1 Instituto Federal de Educação, Ciência e Tecnologia do Ceará. E-mail: lucasilva@ifce.edu.br, Link do Lattes: http://lattes.cnpq.br/5107720953708408

2 Instituto Federal de Educação, Ciência e Tecnologia do Ceará. E-mail: sousa.j.a.ifce@gmail.com, Link do Lattes: http://lattes.cnpq.br/3998748656209220

3 Instituto Federal de Educação, Ciência e Tecnologia do Ceará. E-mail: silva.a.ifce@gmail.com, Link do Lattes: http://lattes.cnpq.br/8039856827553155 


\section{Introdução}

A sociedade atual se apresenta em um contexto complexo, indicando talvez como problemática central, o desafio ambiental. De fato, o meio ambiente tem sido alvo de formulações de políticas, programas e projetos, embora muitas dessas iniciativas tenham caráter duvidoso ${ }^{4}$. Esses esforços têm se dado em decorrência dos impactos ambientais causados pela utilização predatória dos recursos naturais. A crise ambiental colocou a descoberto a insustentabilidade ecológica da racionalidade econômica (LEFF, 2006, p. 226).

$\mathrm{O}$ caminho que a humanidade tomou em relação ao meio ambiente, marcadamente a partir da década de 1970, tem se concretizado em uma devastação da natureza sem precedentes em toda a história da humanidade (PORTO-GONÇALVES, 2018). A crise ambiental veio questionar a racionalidade e os paradigmas teóricos que impulsionaram e legitimaram 0 crescimento econômico, negando a natureza (LEFF, 2001, p. 15). A indústria, agricultura, comércio e serviços, enfim, todos os setores da economia, além das práticas cotidianas de cada pessoa causa prejuízos diversos a todos os ecossistemas, reverberando perdas também para as sociedades. A cultura consumista, típica do nosso tempo, impede uma mudança mais latente no nosso estilo de vida, marcado pela recriação constante de necessidades, portanto, "a crise ambiental é fundamentalmente cultural" (RODRIGUES; SILVA, 2017, p. 175).

Esse cenário preocupante, estimula a criação de projetos e iniciativas, mesmo que em pequena escala, para o alcance da racionalidade ambiental. Embora consideremos que mudanças mais amplas no seio de uma sociedade que comumente negligencia a questão ambiental (e essas mudanças são sem dúvida as mais importantes), merecem destaque também as iniciativas em pequena escala, conquanto não alcancem sozinhas alterações mais profundas.

A construção da racionalidade ambiental certamente não se concretiza de forma simples, passa por mudanças culturais, de alteração de estilos de vida, sendo regida segundo os preceitos ecológicos. Nesse sentido a Educação Ambiental emerge e se funda em um novo saber que ultrapassa 0 conhecimento objetivo das ciências (LEFF, 2009, p. 17).

A escola como espaço privilegiado para a formação humana, tem papel estratégico na constituição da racionalidade ambiental. A partir da formação de sujeitos políticos, mais amplamente, capazes de agir reflexiva e criticamente na sociedade e, mais especificamente, preocupados com os fundamentos ecológicos desta. Assim, a sociedade pode dispor de profissionais ambientais conscientes de seu papel, compartilhando com outros profissionais ambientais de outras áreas, a complexidade das questões que envolvem este campo (CARVALHO, 2012). E ainda com o apoio de outros níveis educacionais, como

\footnotetext{
4 Para isso só observar políticas de desenvolvimento sustentável que tentam solucionar as questões ambientais a partir do desenvolvimento econômico, adotando como medidas de compensação do impacto ambiental, estratégias de plantio de árvores que em sequência também servem aos objetivos do capital.
}

revista brasileira educação ambiental 
universidade e institutos, que desenvolvem projetos voltados a práticas ecológicas.

É na escola que, frequentemente, os alunos desenvolvem suas primeiras experiências com a Educação Ambiental. Infelizmente, a maneira como muitas das vezes os conteúdos são abordados fazem com que haja uma padronização nas relações entre humanos e meio ambiente, uma lógica de "sujeito-objeto" (PINHEIRO, 2015, p. 25).

Desse modo, acrescentar ações que busquem a sustentabilidade como metodologias de ensino, é fundamental para que a escola desenvolva nos alunos capacidades de analisar os problemas ambientais, tanto em caráter local quanto global, intervindo e interagindo com seus colegas, buscando a superação do individualismo que tanto marca as relações humanas com o meio ambiente (SANTOS, et al., 2017).

Com isto, foram realizadas ações de Educação Ambiental, tendo como foco o fortalecimento da sustentabilidade no espaço escolar, partindo do reconhecimento da necessidade de alteração do padrão cultural de utilização dos recursos naturais pela humanidade. Tais ações, fazem parte das atividades do projeto "Ecoresidente: Educação Ambiental para sustentabilidade no espaço escolar" desenvolvido pelo Laboratório de Estudos Ecológicos e Ambientais do Bioma Caatinga - LEEABC do Instituto Federal de Educação Ciência e Tecnologia do Ceará, Campus de Quixadá. Tal projeto, semelha-se a residência pedagógica e a residência médica, e consiste na permanência de estudantes de ensino superior dos cursos de Licenciatura em Geografia e Engenharia Ambiental e Sanitária, em escolas de ensino médio do município de Quixadá-CE, desenvolvendo ações de Educação Ambiental em espaço escolar, contando com a participação de alunos, professores, direção, funcionários e comunidade externa.

O projeto "Ecoresidente" está edificado sobre os quatro eixos de atuação estabelecidos pela Lei estadual o 16.290 de 21 de julho de 2017 (CEARÁ, 2017), que estabelece um prêmio e selo Escola Sustentável para as escolas estaduais do estado do Ceará. São eles: espaço físico, educomunicação, gestão ambiental escolar e currículo. Tendo como objetivo, possibilitar o desenvolvimento de ações de Educação Ambiental, envolvendo toda a comunidade escolar e comunidade externa, disseminando os princípios ecológicos e sustentáveis para se alcançar a racionalidade ambiental e a formação de sujeitos ecológicos no espaço escolar, tornando a escola mais sustentável.

Assim, é necessário de início definir racionalidade ambiental e sujeito ecológico. O primeiro se constitui como uma categoria que abrange as relações entre organizações, instituições, movimentos e práticas sociais que se desenrolam no campo conflitivo do ambiental e influenciam as formas de acesso, usufruto e percepção dos recursos naturais, bem como a qualidade de vida e os estilos de desenvolvimento das populações (LEFF, 2006). Segundo Carvalho (2012), o sujeito ecológico seria o "tipo ideal, portador de valores 
éticos, atitudes e comportamentos ecologicamente orientados, que incidem sobre o plano individual e coletivo" (p. 23), sendo ainda "[...] tributário de um projeto de sociedade socialmente emancipada e ambientalmente sustentável" (CARVALHO, 2005, p. 56).

\section{Metodologia}

A pesquisa caracteriza-se como um estudo qualitativo, exploratório e descritivo, com enfoque na pesquisa-ação, tipo de investigação-ação que segue um ciclo no qual se aprimora a prática pela oscilação sistemática entre agir no campo da prática e investigar a respeito dela (TRIPP, 2005). Nesse sentido foi possível uma intervenção dentro de uma problemática social: a necessidade de desenvolvimento de ações de Educação Ambiental no ambiente escolar.

O tempo-espaço para aplicação das ações discutidas neste trabalho foi a Escola Estadual de Ensino Médio José Martins Rodrigues, uma das contempladas pelo projeto, durante os meses de agosto a dezembro de 2019. A escolha dessa escola para atuação dos ecoresidentes se deu por critérios de vulnerabilidade social, tendo em vista que se localiza em uma área periférica da cidade de Quixadá-CE e recebe alunos dos distritos rurais do município, sendo majoritariamente alunos de famílias menos abastadas. Embora a escola conte com um anexo em outro distrito, as ações foram desenvolvidas apenas na sede da escola.

Os sujeitos foco das ações de EA foram os alunos da escola, majoritariamente dos primeiros e segundos anos da escola. Os alunos dos terceiros anos não participaram das ações devido a própria opção da escola, que preferiu deixá-los focados nas provas externas e de ingresso no Ensino Superior, como o ENEM.

Para a concretização das ações desenvolvidas e para 0 desenvolvimento dos princípios adotados no Ecoresidente, foi necessário a definição de algumas etapas, a saber: 1) Levantamento bibliográfico; 2) planejamento das ações; 3) realização das ações; e, 4) avaliação das ações desenvolvidas. A descrição de cada etapa está disposta a seguir.

$\mathrm{Na}$ primeira etapa, buscamo-nos alicerçar na bibliografia especializada sobre a questão ambiental, racionalidade ambiental e a formação do sujeito ecológico, bem como na legislação vigente, tanto a nível nacional como estadual. Assim, buscamos o subsídio em livros, capítulos de livros e publicações em revistas especializadas. Embora o levantamento bibliográfico tenha sido a primeira etapa, ocorreu concomitantemente às demais etapas desde o início do projeto, permanecendo até a finalização deste texto.

$\mathrm{Na}$ segunda etapa, levamos em consideração o contexto da escola, embora as ações tenham se modificado ao longo do processo. Mas de início

tomamos como base para a elaboração e definição das ações os oito 
aspectos $^{5}$ dispostos na Lei oㅜ 11.290 de 21 de julho de 2017, que definem aspectos avaliativos referentes a atributos que a escola deve cumprir para conseguir o Prêmio e Selo Escola Sustentável (CEARÁ, 2017).

Assim, foi elaborado e redigido um Plano de Educação Ambiental (PEA), onde estava descrito as ações planejadas, seus objetivos e metas, além de um cronograma de aplicação destas ações. Conquanto o planejamento tenha sido realizado previamente, se concretizou de maneira flexível, na medida em que alteramos algumas ações e incluímos outras com o passar do tempo de desenvolvimento do projeto e ainda alteramos algumas vezes as datas em decorrência de contratempos de natureza material e relacionados a atividades escolares elaboradas pela escola.

$\mathrm{Na}$ terceira etapa, parte-se para a concretização das ações previamente definidas no Plano de Educação Ambiental (PEA), em que foi preciso providenciar os materiais necessários para a concretização das ações. Privilegiou-se a reutilização de materiais e ferramentas já disponíveis na escola, não havendo essa disponibilidade, solicitamos a outras instituições.

A partir da concretização das ações, na última etapa buscou-se realizar uma avaliação com os membros do projeto ecoresidente e com os participantes do projeto no espaço escolar. No processo avaliativo elencou-se os pontos fortes e aqueles que necessitavam melhorar, assim como os benefícios para a prática do ensino e aprendizagem na escola.

\section{Resultados e discussões}

\section{Diagnóstico inicial}

Para iniciar o processo de implementação de ações de Educação Ambiental em espaços escolares, foi necessário conhecer as ações já relacionadas a valorização do meio ambiente, ou seja, práticas sustentáveis que já são feitas e estão consolidadas ou em consolidação na escola. Conquanto não possamos negligenciar o aspecto estrutural, também não se pode esquecer o aspecto político e pedagógico expresso no Projeto PolíticoPedagógico (PPP) da escola, pois é nele:

\footnotetext{
5 I - utilização no espaço físico da escola de materiais construtivos mais adaptados às condições locais e de um desenho arquitetônico que permita dotar a escola de conforto técnico e acústico, e garanta acessibilidade; II - gestão eficiente da água, saneamento ecológico, destinação adequada de resíduos; III - uso de energias limpas; IV - práticas de estímulo à segurança alimentar e nutricional; V - práticas de respeito ao patrimônio cultural e ecossistemas locais; VI - gestão escolar compartilhada com a comunidade escolar e seu entorno; VII - práticas de promoção dos direitos humanos e valorização da diversidade cultural, étnico-racial e de gênero existente; VIII - promoção do conhecimento das condições do bioma local e do clima (CEARÁ, 2017).
} 
[...] onde se explicita a concepção pedagógica do corpo docente, as bases teórico-metodológicas da organização didática, a contextualização social, econômica, política e cultural da escola, a caracterização da clientela escolar, os objetivos educacionais gerais, a estrutura curricular, as diretrizes metodológicas gerais, o sistema de avaliação do plano, a estrutura organizacional e administrativa" (LIBÂNEO, 2006, p. 230).

No reconhecimento da política na EA, percebe-se alguns entraves, na medida em que muitas das ações para serem implementadas necessitavam de diálogo com os professores, colaboradores e com a direção escolar. Durante essa fase do diagnóstico, surgiram divergências e entraves que indicaram a necessidade de estabelecer novos delineamentos e estratégias para sua superação.

O fato de o projeto político-pedagógico não abranger os princípios da EA também pode ser considerado uma dificuldade: primeiro, por que para inserir esses princípios no PPP exigiria certo esforço institucional da escola, demandando tempo e debates para sua inserção6; segundo, embora a existência desses princípios não garanta sua efetiva concretização, a inexistência deles, abre espaço para justificar a negligência nas práticas docentes cotidianas.

Franco (2014), sublinha que o PPP precisa destacar a relação homemnatureza, particularmente, indicando o aluno como sujeito interativo do processo e dotando-o como capaz de encontrar os problemas ambientais, podendo traçar soluções articuladas com o conhecimento científico e possibilitando que ele próprio se reconheça como causador dos problemas ambientais contemporâneos, conquanto possa, a partir de sua atuação, contribuir para sua alteração. Assim, o projeto político-pedagógico escolar, que considera os princípios de uma EA crítica poder-se-ia "contribuir para uma mudança de valores e atitudes, formando um sujeito ecológico capaz de identificar e problematizar as questões socioambientais e agir sobre elas" (CARVALHO, 2012, p. 158-159).

A Lei de Diretrizes e Bases da Educação (LDB), instituída pela lei 9.394/1996 trata a Educação Ambiental de forma muito discreta, citando-a apenas indiretamente em seu Art. 26, parágrafo $1^{\circ}$, destacando que os currículos devem abranger, entre outros, o conhecimento do mundo físico e natural (BRASIL,1996). No ano de 2012, o parágrafo $7^{\circ}$ deste mesmo artigo foi incluído pela lei $\mathrm{n}^{\circ} 12.608 / 2012$, onde tornava obrigatório a inclusão dos

\footnotetext{
${ }^{6}$ A inserção dos princípios da educação ambiental no Projeto Político-Pedagógico e no currículo da escola é uma das necessidades expressas na Lei 11.290/2017 (CEARÁ, 2017), especificamente no eixo currículo, para que a escola seja premiada com o selo escola sustentável.
} 
princípios da Educação Ambiental de forma integrada ao currículo, no entanto, no ano de 2017, a lei 13.415/2017, revogou este parágrafo e deixou a critério do sistema de ensino a inclusão de projetos e pesquisas por meio de temas transversais.

Conforme a Resolução CNE/CP no 2/2012, no seu Art. 7, a EA deve ser integrada nos projetos pedagógicos e institucionais da instituição de ensino, no caso da educação básica, não devendo ser componente curricular específico, mas abordada, conforme o Art. 16, especificamente nos incisos I ao III, da mesma resolução, de modo transversal, mediante temas relacionados com o meio ambiente e a sustentabilidade socioambiental; como conteúdo dos componentes já constantes do currículo; pela combinação de transversalidade e de tratamento nos componentes curriculares (BRASIL, 2012). A Política Nacional de Educação Ambiental (PNEA), Lei 9.795/1999, bem como o Decreto № 4.281/2002, que regulamenta a citada lei, também destaca a EA não como componente específico do currículo escolar, mas como tema que deve ser abordado de modo transversal (BRASIL, 1999; BRASIL, 2002).

Os conteúdos programáticos presentes no PPP da EEM José Martins Rodrigues (CEARÁ, 2019), apresentam caráter parcialmente crítico, buscando desenvolver nos alunos, capacidades e habilidades para que se tornem sujeitos ativos em sua comunidade.

Com relação as discussões sobre a temática ambiental, disciplinas que compreendem a área das ciências humanas, abordam a temática de uma forma holística, destacando-se as disciplinas de Sociologia, Geografia e História, onde há uma grande preocupação em trabalhar como as relação homem-natureza-economia influenciam no modo de uso do espaço e suas influências na manutenção de um ambiente ecologicamente saudável.

Neste mesmo caminho, as disciplinas que compreendem a área de linguagens e códigos também buscam abordar em suas aulas a questão ambiental, dentre elas, a educação física aposta nas trilas ecológicas como forma de ensino aprendizagem, buscando a manutenção e valorização do bioma local e a formação de sujeitos ecologicamente responsáveis.

No currículo das disciplinas da área de matemática e suas tecnologias e ciências naturais e suas tecnologias os conteúdos trabalhados sobre o meio ambiente, são abordados a partir das discussões inerentes as respectivas disciplinas. Assim, não há um destaque para as relações predatórias entre sociedade e natureza, numa abordagem crítica, pois "[...] os conhecimentos técnico-científicos sobre os processos ambientais só têm sentido como conteúdos educativos da Educação Ambiental se ligados de forma indissociável aos significados humanos e sociais desses processos" (TOZONIREIS, 2002, p. 90). 
Destaque-se que essa análise não negligencia a possibilidade de um tratamento destacado no cotidiano da sala de aula, na medida em que pode ser abordado de maneira não explicitada no próprio currículo da escola. Conforme Tozoni-Reis (2001) o processo educativo em Educação Ambiental se efetiva na problematização do papel do homem na biosfera, possibilitando a compreensão das complexas relações entre sociedade e natureza, bem como os processos históricos que balizam a organização das relações sociais.

Assim, consideramos imprescindível para a efetiva concretização da racionalidade ambiental e formação de sujeitos ecológicos, a partir da EA, o apoio político-pedagógico expresso no PPP, bem como sua concretude nas ações cotidianas da escola. Assim, ter esses aspectos em mente contribui para uma melhor operacionalização dos objetivos propostos.

A EEM José Martins Rodrigues, circunscrita no âmbito do sistema estadual de ensino, dispõe de algumas práticas dignas de nota. A partir do projeto Luzes para Aprender, uma parceria entre a Enel Brasil e a Organização dos Estados Ibero-Americanos para a Educação, a Ciência e a Cultura (OEI) foram instalados na escola dezoito placas fotovoltaicas, proporcionando uma geração média de energia estimada em 740 kWh, com redução no ano 2015 de $34 \%$ do consumo de energia e de uma tonelada de emissão de $\mathrm{CO}^{2}$ por ano (DIÁRIO DO NORDESTE, 2015). A existência dessa tecnologia na escola, fato que é sem dúvidas singular no contexto das escolas estaduais no Ceará, poderia também ser mais bem aproveitado, no sentido da valorização de um dos recursos mais abundantes na região onde está inserida. Assim, é muito importante a incorporação de metodologias de ensino que valorize e contextualize esse tipo de prática na escola, inserindo a sustentabilidade.

No âmbito da valorização do meio ambiente local, destacadamente das condições hidrológicas da região semiárida, foi implantada, uma cisterna de placa que tem capacidade de armazenar cerca de 52 mil litros. A cisterna de placa é uma estrutura feita com placas pré-moldadas de cimento e areia, comumente utilizada para armazenar água da chuva coletada nos telhados das casas ou de estruturas cobertas (no caso da escola a água é coletada a partir da cobertura da quadra poliesportiva) nos períodos chuvosos no semiárido, servindo para ser utilizada nos períodos de escassez hídrica. A cisterna foi implantada na escola sob o Programa Cisterna na Escola, feito em parceria com o Instituto Antônio Conselheiro (IAC), Articulação do Semiárido Brasileiro (ASA) e o Ministério do Desenvolvimento Social, este último o responsável pelo aporte dos recursos para a implementação da tecnologia.

A valorização do meio ambiente local, a partir da inserção de uma educação para a convivência com o semiárido, valorizando, portanto, um paradigma cultural orientador do desenvolvimento sustentável, que utiliza para concretização tecnologias simples e de baixo custo para as populações rurais do semiárido brasileiro (SILVA, 2008). 


\section{As ações do Ecoresidente}

Jornada de Educação Ambiental e Lançamento do projeto Ecoresidente

Esse evento não foi previamente planejado como uma ação, embora tenha se constituído como momento para troca de experiência. Aconteceu no dia 18 de setembro de 2019 e teve o objetivo de divulgar ações, pesquisas e projetos voltados a Educação Ambiental produzidas no Instituto Federal de Educação, Ciência e Tecnologia do Ceará (IFCE), Campus Quixadá-CE, bem como divulgar o projeto aqui em apreço. Inicialmente, ocorreu uma palestra do Secretário do Meio Ambiente do Estado do Ceará, sobre o selo e prêmio escola sustentável, concedido pelo governo do estado e posteriormente a apresentação de trabalhos acadêmicos produzidos pelos alunos do IFCE.

Todas as escolas contempladas com o projeto foram convidadas a participar. A EEM José Martins Rodrigues, contou com a participação do diretor e de 30 alunos. Assim, os alunos da escola puderam conhecer o projeto e assistir a apresentações de trabalho dos alunos do IFCE que desenvolviam projetos e pesquisas voltados a Educação Ambiental; coisas simples, mas bastante instigantes como a reutilização de cartuchos de pincel para produzir chaveiros ecológicos, a reutilização de pneus para produção de bancos e mesas, até trabalhos voltados à política ambiental do IFCE.

O benefício esperado com a realização deste evento foi a possibilidade de estimular a participação dos alunos, professores e direção das escolas contempladas com 0 projeto. Para além disso, a socialização de conhecimentos e práticas que poderiam ser reproduzidas nos espaços da escola e consequentemente o estímulo a adoção de práticas ecológicas e sustentáveis.

\section{Plantio de mudas nativas da Caatinga}

Frequentemente, as potencialidades da Caatinga são desprestigiadas em função de uma associação a um ambiente de solos pedregosos e vegetação com pouca heterogeneidade fisionômica (BRASIL, 2002). Esse discurso chegou aos livros didáticos e corroborou ainda mais para a falta de conhecimento da população sobre o bioma (SENA, 2011).

Com a finalidade de articular o espaço escolar com a promoção da valorização do bioma local, foi promovido no âmbito do projeto ecoresidente, o plantio de mudas nativas da Caatinga. Essa ação foi desenvolvida em parceria com a Coordenadoria Regional de Desenvolvimento da Educação (CREDE 12), que forneceu as mudas para o plantio na escola, e com o Laboratório de Estudos Ecológicos e Ambientais do Bioma Caatinga (LEEABC), que forneceu os recursos materiais e logísticos necessários para a realização desta atividade.

Inicialmente, foi feito um reconhecimento dos locais que poderiam 
da escola pelas raízes e galhos das espécies plantadas. Assim, tendo conhecimento das necessidades da escola, partimos para a escolha das espécies, tendo auxílio do responsável pelo setor de Educação Ambiental da CREDE 12, que é biólogo e conhecedor das espécies adequadas para plantar na escola.

Além da valorização do bioma local, a atividade buscou a substituição do Nim indiano (Azadirachta indica), que é muito presente na Escola, por plantas nativas.

Trazido da Índia o Nim teve seu cultivo desenvolvido à margem de pesquisas silviculturais com foco comercial (NEVES; CARPANEZZI, 2009). Infelizmente, devido ao manejo inadequado, o Nim passou a ser cultivado em solos e climas que não atendem as exigências da espécie, tornando-a assim uma espécie invasora (op. cit). Com um crescimento rápido e boa adaptação, passou a ser muito usado pela população para arborização e sombreamento em suas residências e praças das cidades (MALAVASI; MALAVASI, 2001).

Com um manejo de maneira inadequada da árvore o Nim passou a ser um vilão para o desenvolvimento de outras espécies nativas, assim como afirma Leão et al (2011), ao defender que a introdução de espécies invasoras é um dos motivos principais para a perda da diversidade natural.

\section{Minicurso sobre coleta, herborização e inventário florístico}

Essa atividade teve o objetivo de introduzir os alunos e professores na construção de um inventário florístico (o qual chamamos de acervo botânico, conjunto de folhas, flores ou frutos desidratados utilizados para apreciação, estudo e pesquisa). Participaram dez alunos e dois professores da escola. $\mathrm{Na}$ ocasião contamos com a colaboração de uma bolsista do curso de Engenharia Ambiental e Sanitária do IFCE, Campus de Quixadá, que ministrou o minicurso. Uma prensa foi doada para a escola, possibilitando que os alunos realizem a desidratação dos materiais e sua posterior catalogação.

Para o desenvolvimento do acervo botânico algumas ponderações merecem ser levantadas. Uma das principais é a dificuldade em coletar material no período seco, quando a grande maioria das espécies da Caatinga perde sua folhagem, impossibilitando sua coleta. No período seco pode ser coletado espécies de tipo sempre verde, que preservam sua folhagem, como o Juazeiro e Jucá.

Com os conhecimentos adquiridos, os professores e alunos poderão, em coletividade, desenvolver o acervo botânico. A constituição do acervo botânico feito pelos próprios alunos com a supervisão dos professores, poderá ser utilizado para apreciação de toda a comunidade escolar e principalmente como material didático para utilização nas aulas, tornando-as mais dinâmicas e prazerosas (BRAZ; LEMOS, 2014). 
Tendo em vista o caráter técnico das aulas sobre Botânica, o acervo botânico surge não só como iniciativa na valorização do bioma local, mas também como estratégia facilitadora para o ensino-aprendizagem, uma vez que proporciona aos alunos um contato maior com o conteúdo exposto em sala, fazendo com que o mesmo sinta-se menos receoso com os conteúdos relacionados ao tema (op.cit.).

\section{"Fala Martins!" como estratégia de educomunicação7 socioambiental}

A educomunicação vem se estabelecendo como um campo de prática social fundamentado em processos de construção coletiva, propondo a revisão crítica dos modelos de intervenção consolidados e impostos a partir de referenciais externos (TOTH; MERTENS; MAKIUCHI, 2012). Desenvolver ações voltadas à EA sem a oportunidade de divulgá-las, convidando os sujeitos da escola a participar pode se tornar uma perda de potencial de alcance das ações. Assim, por ocasião da criação do jornal da escola "Fala Martins!", pudemos divulgar as ações já desenvolvidas no espaço escolar e fora dos muros da escola.

Assim, o jornal "Fala Martins!", para além de um espaço de comunicação e divulgação, pode se constituir em um espaço amplo de conscientização do conjunto dos alunos, professores, funcionários, direção escolar, pais de alunos e amigos da escola, em relação às questões voltadas a valorização, preservação do meio ambiente e crítica do contexto atual de degradação ambiental, caminhando em direção a racionalidade ambiental e a formação de sujeitos preocupados com o futuro do meio ambiente.

Para além de um espaço de divulgação e comunicação do Projeto Ecoresidente, poder-se-ia constituir em espaço para que os alunos possam desenvolver ações de conscientização do restante dos alunos, bem como de assuntos pertinentes às questões ambientais.

Embora na constituição inicial do espaço de comunicação cedido ao projeto, não tenha contado com a participação dos alunos como os sujeitos produtores de conteúdo, o todo do jornal "Fala Martins!" tem se dado de maneira participativa ${ }^{8}$, o que constitui estímulo para quando do desenvolvimento de novas ações de Educação Ambiental, os alunos participantes das ações possam produzir o conteúdo, divulgando, comunicando e convidando a participação dos seus colegas.

${ }^{7}$ Para o conhecimento do conceito de educomunicação desde sua origem atrelada ao movimento contrahegemônico de comunicação dos povos da América Latina e ligado entre outros, à pedagogia de Paulo Freire, ver Freitas (2015).

${ }^{8}$ Os alunos e professores produzem conteúdo referente a dicas para o bom desempenho em avaliações externas, além da produção de resenhas de livros, poesias etc. 


\section{Considerações finais}

A constituição da racionalidade ambiental pode ter grande contribuição da Educação Ambiental, seja em espaços escolares, como foi o Projeto Ecoresidente, seja em espaços não escolares. Embora a ecoresidência não tenha se constituído acoplado ao currículo escolar, fato que potencializaria as suas ações, atendeu a um público razoável de alunos da EEM José Martins Rodrigues.

Assim, a partir deste projeto, foi possível a contribuição para a formação de sujeitos ecológicos, utilizando-se de estratégias e ações voltadas a Educação Ambiental. Certamente, a necessidade do desenvolvimento de mais ações de EA são importantes para o incremento da sustentabilidade no espaço escolar, no currículo, enfim, em todas as práticas pedagógicas que compõem a rotina da escola, alunos, professores e direção, além da necessidade de intensificação da integração com a comunidade externa.

Ações semelhantes ainda podem ser estimuladas em espaços não escolares, como praças, estradas, prédios públicos, empresas privadas, e organizações não governamentais. Tudo convergindo para a formação de sujeitos preocupados com as questões ambientais que são tão evidentes nos dias de hoje. Assim, com a constituição de sujeitos ecológicos, e em decorrência, a adoção de práticas sustentáveis e ecológicas nas práticas pessoais, profissionais (profissionais ambientais) e pedagógicas (educadores ambientais), afetando o todo da sociedade, poder-se-ia alcançar a racionalidade ambiental, diminuindo a influência da razão econômica na tomada de decisão em relação as políticas, programas e projetos que afetam a sociedade.

Certamente, para além da constituição da EEM José Martins Rodrigues em um espaço escolar mais sustentável, a ecoresidência contribuiu para a formação dos ecoresidentes, enquanto futuros educadores ambientais.

\section{Agradecimentos}

À Pró-reitoria de Extensão (ProExt) do Instituto Federal de Educação, Ciência e Tecnologia do Ceará (IFCE); ao Laboratório de Estudos Ecológicos e Ambientais do Bioma Caatinga (LEEABC); à Escola de Ensino Médio José Martins Rodrigues.

\section{Referências}

BRASIL. Congresso Nacional. Lei no 9.394, de 20 de dezembro de 1996. Dispõe sobre a Lei de Diretrizes e Bases da Educação. 1996. Disponível em: < http://www.planalto.gov.br/ccivil 03/leis//9394.htm >. Acesso em: 11 de maio. 2020. 
BRASIL. Congresso Nacional. Lei no 9.795, de 27 de abril de 1999. Dispõe sobre a Educação Ambiental, institui a Política Nacional de Educação Ambiental e dá outras providências. 1999. Disponível em: $<$ http://www.planalto.gov.br/ccivil 03/LEIS/L9795.htm> Acesso em: 25 de jan. 2020.

BRASIL. CONSELHO NACIONAL DE EDUCAÇÃO (CNE). Resolução no $\mathbf{2}$, de 15 de junho de 2012. Estabelece as Diretrizes Curriculares Nacionais para a Educação Ambiental. 2012. Disponível em: < http://portal.mec.gov.br/dmdocuments/rcp002 12.pdf >. Acesso em: 09 de maio de 2020.

BRASIL. Decreto no 4.281, de 25 de junho de 2002. Regulamenta a Lei ㅇ 9.795, de 27 de abril de 1999, que institui a Política Nacional de Educação Ambiental, e dá outras providências. 2002. Disponível em: $<$ http://www.planalto.gov.br/ccivil 03/decreto/2002/D4281.htm>. Acesso em: 25 de jan. 2020.

BRASIL. M. M. A. Biodiversidade brasileira: Avaliação e identificação de áreas e ações prioritárias para conservação, utilização sustentável e repartição dos benefícios da biodiversidade nos biomas brasileiros. Brasília: MMA/SBF, $2002 . \quad$ Disponível em: <https://www.mma.gov.br/publicacoes/biodiversidade/category/142-seriebiodiversidade.html?download=896: serie-biodiversidade-biodiversidade5\&start=40>. Acesso em: 25 de jan. 2020.

BRAZ, N, C; LEMOS, J, R. "Herbário escolar" como instrumento didático na aprendizagem sobre plantas em uma escola de Ensino Médio da cidade de Parnaíba, Piauí. Revista Didática Sistêmica, Rio Grande do Sul, v. 16, n. 2, p. 3-14, 2014.

CARVALHO, I. C. M. A invenção do sujeito ecológico: identidade e subjetividade na formação dos educadores ambientais. In: SATO, M; CARVALHO, I. C. M. Educação Ambiental. Porto Alegre: Artmed, p. 53-65, 2005.

CARVALHO, I. C. M. Educação Ambiental: a formação do sujeito ecológico. 6. ed. São Paulo: Contexto, 2012.

CEARÁ. 12ํㅡㄹ Coordenadoria Regional de Desenvolvimento da Educação. Projeto Político Pedagógico: EEM José Martins Rodrigues. Quixadá: CREDE12, 2019.

CEARÁ. Lei 16.290, de 21 de julho de 2017. Dispõe sobre a criação do Selo Escola Sustentável e concede o Prêmio Escola Sustentável. 2017. Disponível em: $\quad<$ https://www.sema.ce.gov.br/wp-content/uploads/sites/36/2019/01/LElSelo-Escola Sustent\%C3\%A1vel.pdf>. Acesso em: 11 de fev. 2020. 
DIÁRIO DO NORDESTE. Energia solar: escolas públicas do Ceará são contempladas com projeto Luzes para Aprender. 4 de dezembro de 2015. Disponível em: $<$ http://blogs.diariodonordeste.com.br/sertaocentral/educacao/energia-solarescolas-publicas-do-ceara-sao-contempladas-com-projeto-luzes-paraaprender/42808> Acesso em: 30 de jan. 2020.

FRANCO, E. A. S. Projeto Escola \& Universidade: a formação do sujeito ecológico. Revista Brasileira de Educação Ambiental (RevBEA), São Paulo, v. 9, n. 2, p. 436-450, dez. 2014.

FREITAS, J. V. Educomunicação: contextualizando o processo de atribuição de sentidos e significados no delineamento do conceito. Revista Brasileira de Educação Ambiental (RevBea), São Paulo, v. 10, n. 2, p. 149-162, jul. 2015.

LEÃO, T. C. C; ALMEIDA, W. R; DECHOUM, M; ZILLER, S. R. Espécies exóticas invasoras no Nordeste do Brasil: contextualização, manejo e políticas públicas. Recife: Cepan, 2011.

LEFF, E. Complexidade, racionalidade ambiental e diálogo de saberes. Tradução: Tiago Daniel de Mello Cargnin. Educação \& Realidade. v. 34. n. 3, p. 17-24, set/dez, 2009.

LEFF, E. Racionalidade ambiental: a reapropriação social da natureza. Tradução: Luís Carlos Cabral. Rio de Janeiro: Civilização brasileira, 2006.

LEFF, E. Saber Ambiental: sustentabilidade, racionalidade, complexidade, poder. Tradução: Lúcia Mathilde Endlich Orth. Petrópolis: Vozes, 2001.

LIBÂNEO, J. C. Didática. São Paulo: Cortez, 2006.

MALAVASI, U. C; MALAVASI, M. M. Avaliação da arborização urbana pelos residentes - estudo de caso em Mal. Cândido Rondon, Paraná. Ciência Florestal, v. 11, n. 1, p. 189-193, mar. 2001.

NEVES, E. J. M; CARPANEZZI, A. A. Prospecção do cultivo do Nim (Azadirachta indica) no Brasil. Colombo: Embrapa Florestas, 2009.

PINHEIRO, P. S. L. Um estudo sobre o antropocentrismo nos livros didáticos de ciências naturais para os anos iniciais do ensino fundamental. Dissertação (Mestrado), Programa de Pós-graduação em Educação Científica e Formação de Professores. Universidade Estadual do Sudoeste da Bahia. Jequié - Bahia: UESB, 2015.

PORTO-GONÇALVES, C. W. A globalização da natureza e a natureza da globalização. 8. ed. Rio de Janeiro: Civilização Brasileira, 2018.

RODRIGUES, J. M. M. SILVA, E. V. Educação Ambiental e Desenvolvimento Sustentável: problemática, tendências e desafios. 5. ed. Fortaleza: Expressão Gráfica e Editora, 2017. 
SANTOS, C, R. et al. Reciclagem de papel e o desenvolvimento de ações sustentáveis: uma parceria entre o Pibid interdicisplinar em Educação Ambiental e a Com-vida escolar. Revista Brasileira de Educação Ambiental (RevBea), São Paulo, v. 12, n. 2, p. 114-126, jun. 2017.

SENA, L, M, M. Conheça e conserve a Caatinga: O Bioma Caatinga. v. 1. Fortaleza: Associação Caatinga, 2011.

SILVA, R. M. A. Entre o combate à seca e a convivência com o semi-árido: transições paradigmáticas e sustentabilidade do desenvolvimento. Fortaleza: Banco do Nordeste do Brasil, 2008.

TOTH, M; MERTENS, F; MAKIUCHI, M. F. R. Novos espaços de participação social no desenvolvimento sustentável: as contribuições da educomunicação. Ambiente \& Sociedade, São Paulo, v. 15, n. 2, p. 113-132, maio/ago. 2012.

TOZONI-REIS, M. F. C. Educação e Sustentabilidade: relações possíveis. Olhar de professor, Ponta Grossa, v. 14, n. 2, p. 293-308, nov/dez. 2011.

TOZONI-REIS, M. F. C. Formação dos educadores ambientais e paradigmas em transição. Ciência \& Educação, Bauru, v. 8, n. 1, p. 83-96, 2002.

TRIPP, D. Pesquisa Ação: Uma Introdução Metodológica. Educação e Pesquisa, São Paulo, v. 31 n. 3, p. 443-466, set./dez. 2005. 